\title{
OPTIMISING 3-PHENYL-1,4,2-DIOXAZOL-5-ONE AS AN ELECTROLYTE ADDITIVE FOR LITHIUM-ION CELLS
}

\author{
TOREN HYNES* \\ Department of Chemistry, Dalhousie University \\ Halifax, NS, Canada
}

\begin{abstract}
An effective method to reduce carbon dioxide emissions is to switch to renewables for energy generation and transportation. Since current sources of renewable energy, such as wind and solar, are intermittent, it is essential to find ways to store energy to match supply and demand. If vehicles are to be powered by renewable energy, they need portable energy storage. Currently, lithium-ion batteries are one of the most viable solutions for energy storage. Extending the lifespan of lithium-ion batteries is the goal of this research, carried out with Dr. David Hall of Dr. Jeff Dahn's research group at Dalhousie University in late 2017. We developed and tested a chemical compound, 3-phenyl-1,4,2-dioxazol-5-one (PDO), which greatly improves the lifespan of lithium-ion batteries. One percent of this by weight in a cell's electrolyte, along with two percent ethylene sulfate, will extend a battery's lifespan more than three-fold over those containing conventional vinylene carbonate-containing electrolyte.
\end{abstract}

\section{INTRODUCTION}

In the scientific community, it is generally agreed that in order to slow the current increase in global temperatures and the resulting weather-related disasters, fossil fuels must be phased out as soon as possible (World Meteorological Organization, 2018). ${ }^{1}$ To reduce emissions, several jurisdictions will be phasing out internal combustion vehicles. Several cities, including Paris, Madrid, Athens, and Mexico City, are expected to phase out the sale of new diesel cars by 2025 (Dahn, 2018). Norway will ban the sale of new internal combustion cars by 2025 (Dahn, 2018), followed by Denmark in 2030 (Nielson 2018), France and British Columbia in 2040 (Gordon \& Grebler 2018), ${ }^{2,4}$ and the United Kingdom by 2050 (Dahn 2018).

\footnotetext{
* Author to whom correspondence should be addressed: toren.hynes@dal.ca
} 
To maximise the emission reductions afforded by switching to electric vehicles, their energy must come from renewable resources, such as wind or solar. Although renewables are quickly becoming the most economically viable means of energy production, they are intermittent. Their energy must be stored when their supply is not sufficient to meet demand (Dahn 2018). While energy can be stored using pumped hydroelectricity, there are only limited numbers of suitable sites for such projects worldwide, so, for now, rechargeable batteries will be the most important means of storing energy, whether for stationary or portable applications (Dahn 2018).

Currently, the most practical secondary battery is the lithium-ion battery, widely used in portable electronic devices and electric vehicles, such as the Tesla Model 3, Nissan Leaf, and Chevrolet Bolt (Tesla 2019). The advantages of lithium-ion batteries include high energy density, long cycle lifetime, low self-discharge, fast recharging, ability to be made into a wide variety of shapes and sizes, and relatively low cost (Dahn 2018). A schematic diagram of a typical lithium-ion cell is shown in Fig 1.

Standard lithium-ion cells, as used in cell phones or power tools, may last only approximately 400 full charge/discharge cycles $(100 \%$ to $0 \%$ capacity) before losing $20 \%$ of their original capacity, the usual

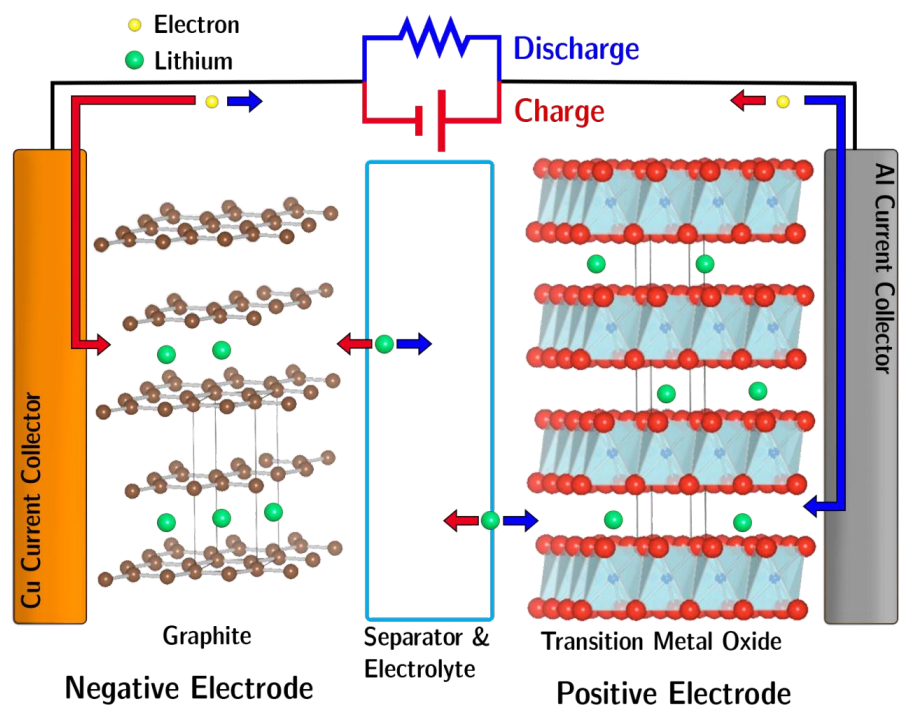

Fig 1 Diagram of a typical lithium-ion cell (Louli 2017). 
criterion for end of life (Ecker et al. 2014). Such cells, however, are not suitable for grid powerstorage applications, where they must last for several decades at least (Dahn 2018). Therefore, it is desirable to increase cycle and calendar life of lithium ion batteries as much as possible.

A vital component of every lithium-ion cell, that is not shown in Fig 1, is the solid-electrolyte interphase (SEI), a thin film between the electrolyte (liquid that conducts electrons) and the graphite particles in the negative electrode. This film is ionically conductive (i.e. $\mathrm{Li}^{+}$ ions can move through it to get into the graphite), but electrically insulating Verma et al. 2010.

If a cell is made using 1.2M LiPF in 3:7 EC:DMC, it will rapidly degrade during cycling, as the SEI formed is not very stable (Seo et al. 2014, Wang et al. 2014a, b). In order to prevent this, another chemical, known as an additive, is typically added to the electrolyte in a few weight percent. Because only small amounts are used, the cost of the cell is not significantly increased (Xu 2004, 2014). Common chemicals used (Fig 2) include vinylene carbonate (VC) (Aurbach et al. 2002, Burns et al. 2013a, Lee et al. 2005, Xia et al. 2014a), fluoroethylene carbonate (FEC) (Etacheri et al. 2012, Ma et al. 2014, Ryou et al.2010), ethylene sulfate (1,3,2-dioxathiolane-2,2-dioxide, DTD) (Li et al. 2014, Madec et al. 2014, Xia et al. 2014b), lithium difluorophosphate (LFO) (Liu et al. 2018, Zhai et al. 2018, Hong et al. 2018), methylene methanedisulfonate (MMDS) (Xia et al. 2015, Xia et al. 2014c), and tris(trimethylsilyl) phosphite (TTSPi) (Han et al. 2015, Koo et al. 2015, Mai et al. 2014,Yim \& Han 2017). Some additives, such as VC and FEC, help build a more resilient SEI,(Jin et al. 2018) while others, such as DTD and MMDS, are thought to be involved in forming a film over the positive electrode, although their precise mechanism of action remains unknown.

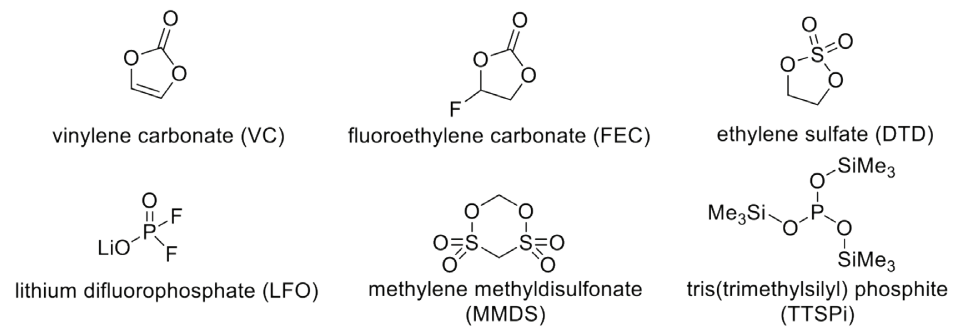

Fig 2 Structures of some commonly used lithium-ion battery electrolyte additives, where Me is a methyl group. 
In the late summer of 2017, Wagner et al. published a paper in which 3-methyl-1,4,2-dioxazol5-one (MDO), an amidating agent (compound for adding an amide function group by creating a $\mathrm{C}-\mathrm{N}$ bond), a class of compounds never used before as an electrolyte additive, was shown to make an excellent $\mathrm{SEI}$ on graphite in a $\mathrm{LiNi}_{0.5} \mathrm{Mn}_{0.3} \mathrm{Co}_{0.2} \mathrm{O}_{2}$ (NMC532)/graphite cell using $1 \mathrm{M} \mathrm{LiPF}_{6}$ in propylene carbonate (PC) (Roser et al. 2017) ${ }^{33}$ a cyclic carbonate solvent that usually rapidly exfoliates graphite on the negative electrode, thereby destroying the cell (Xu 2004).

Wagner et al. (2017) found that cells containing 2\% (by weight) MDO in the electrolyte reached 450 charge/discharge cycles at $25^{\circ} \mathrm{C}$ before losing $20 \%$ of their original capacity, while cells containing $2 \%$ VC or $2 \%$ FEC suffered $20 \%$ capacity fade by 36 and 87 cycles, respectively. Additionally, the MDO cells had a much higher discharge capacity than either the VC or FEC cells.(Roser et al. 2017)

Since MDO showed impressive performance in PC electrolyte, which usually cannot be used at all in cells with a graphite negative electrode, it was logical to wonder if MDO would similarly benefit cells prepared with EC:DMC electrolyte. However, tests performed by Hall et al. (2018) were not encouraging; MDO-containing cells produced lots of gas in formation (the first charge and discharge cycle when a lithium ion battery is first made). Top-of-charge (4.3V) storage testing at $60^{\circ} \mathrm{C}$ for 500 hours showed significant voltage drop and large volumes of gas production (Hall et al. 2018)

At the same time that MDO was being developed, a related compound, 3-phenyl-1,4,2-dioxazol5-one (PDO, Fig 3) was discovered in work by Park et. Al (2015). Since the precursor to PDO, benzohydroxamic acid, could be obtained commercially, and phenyl containing compounds such as diphenyl carbonate have been shown by Petibon et al. (2015) to be effective additives, Dr. David Hall suggested that I test PDO as an electrolyte additive (Hall et al. 2018).

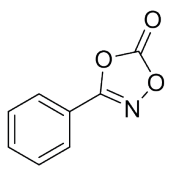

3-phenyl-1,4,2-dioxazol-5-one PDO

Fig 3 Structure of PDO. 


\section{MATERIALS METHODS}

\section{Synthesis of additives}

PDO was synthesised based on a method reported by Park et al. (Fig 4) (Park et al, 2015).<smiles>O=C(NO)c1ccccc1</smiles>

Fig 4 Synthesis of PDO as reported by Park et al.2015) ${ }^{35}$

All solvents and reagents were used as received, without further purification. 1,1carbonyldiimizole (CDI, $\geq 98 \%$ ) was purchased from Oakwood Chemical Inc, and benzohydroxamic acid (98\%) was purchased from Alfa Aesar. Benzohydroxamic acid (5.00g, 36.5 mmol, 1eq) was dissolved in dichloromethane $(120 \mathrm{~mL})$ and stirred. $1,1^{\prime}$-carbonyldiimidazole $(5.92 \mathrm{~g}, 36.5 \mathrm{mmol}, 1 \mathrm{eq})$ was added in one portion. The mixture was stirred for half an hour at room temperature, quenched with $50 \mathrm{~mL}$ of $1 \mathrm{~N} \mathrm{H}_{2} \mathrm{SO}_{4}$, extracted with dichloromethane $(3 \times 40 \mathrm{~mL})$, and dried over $\mathrm{Na}_{2} \mathrm{SO}_{4}$. Volatiles were removed using a rotary evaporator to give crude product, which was recrystallized from a 10:1 mixture of cyclohexane:acetone to give 3-phenyl-1,4,2dioxazol-5-one (PDO).

\section{Lithium-ion cells}

Our study was conducted using pouch cells (Fig 5) (Trask et al. 2014), in which the positive and negative electrodes, along with the separator, were rolled together and inserted into a plastic and aluminum pouch, with current collection tabs sticking out of the pouch. The advantage of using pouch cells, widely used in cell phones and consumer electronics, is that the cells were machine made, greatly improving experimental consistency, and that any gas produced during operation can be measured by recording the change in the cell's volume.

In this study, the negative electrode was copper foil covered with a layer of artificial graphite. The positive electrode was made of aluminum foil covered with a thin layer of a lithium transition metal oxide. Additionally, the pouch was slightly larger than the electrodes, 


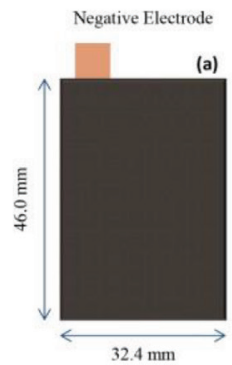

(c)

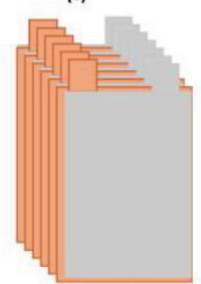

Positive Electrode

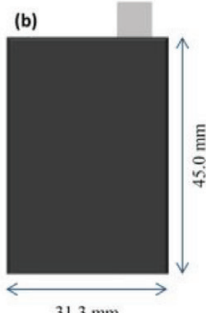

(d)

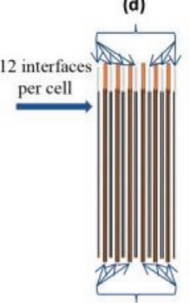

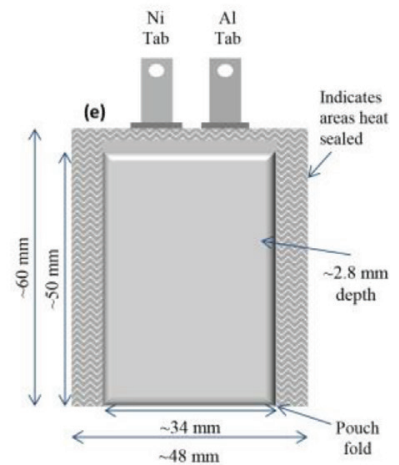

Fig 5 Schematic diagram showing (a) negative electrode, usually made of graphitecoated copper, (b) positive electrode, made of transition-metal oxide coated aluminum foil, (c) and (d) front and side view of electrode stack, (e) complete pouch cell. A polypropylene or polyethylene film (not shown) separates the positive and negative electrodes (Trask et al.2014).

leaving a small empty space, to allow the cells to be cut open for degassing purposes, and resealed.

Dry (no electrolyte) vacuum sealed $\mathrm{LiNi}_{0.6} \mathrm{Mn}_{0.2} \mathrm{Co}_{0.2} \mathrm{O}_{2}$ (NMC622)/ graphite pouch cells, with a capacity of $\sim 230 \mathrm{mAh}$, were purchased from Li-Fun Technology (Tianyuan District, Zhuzhou, Hunan, China). The NMC622 was a conventional polycrystalline material. Before filling, the cells were cut below the heat seal in an argon-atmosphere glovebox, inserted directly from there into a vacuum oven, dried at $80^{\circ} \mathrm{C}$ under vacuum for 14 hours, and returned to the glovebox for filling. Except for PDO, which was purified by recrystallisation from a mixture of cyclohexane and acetone, all solvents, salts, and additives were used as received, without any further purification. All solutions used this work contained $1.2 \mathrm{~mol} \mathrm{~L}^{-1} \mathrm{LiPF}_{6}(\mathrm{BASF}, \geq 99.9 \%$ ) in a $3: 7$ solvent blend, by mass, of ethylene carbonate (EC) and dimethyl carbonate (DMC) (BASF, $\geq 99.9 \%,<20 \mathrm{ppm} \mathrm{H}_{2} \mathrm{O}$ ). The additives, PDO (synthesized and purified at Dalhousie, see above),

VC (BASF, $\geq 99.8 \%$ ), DTD (Guangzhou Tinci Materials Tech. Co. Ltd., $\geq 98 \%$ ), $\mathrm{LiPO}_{2} \mathrm{~F}_{2}$ (LFO, Shenzhen CapChem Tech. Co. Ltd.), TTSPi (TCI America, Inc, $\geq 95 \%$ ), and MMDS (Guangzhou 
Tinci Materials Technology, 98\%), were added singly or as binary or ternary blends in the indicated mass percentages. Cells were filled with $1.0 \pm 0.1 \mathrm{~g}$ of solution, sealed at $-90 \mathrm{kPa}$ (gauge pressure) using a compact vacuum sealer (MSK-115A, MTI Corp.) and immediately held at $1.5 \mathrm{~V}$ to prevent corrosion of the copper current collector during the $\sim 24 \mathrm{hr}$ wetting period that followed at $21-25^{\circ} \mathrm{C}$. Cells then underwent formation of the SEI. Because some gas was expected to be produced during formation, the cells were clamped at $\sim 25 \mathrm{kPa}$ gauge pressure using soft rubber, to push gas bubbles into the empty part of the pouch and prevent them from becoming trapped between the electrodes, resulting in imprecise measurements.

\section{Electrolyte}

The electrolyte in these lithium-ion cells was made of a combination of a cyclic carbonate (Fig 6), ethylene carbonate (EC), which solvates lithium salts well but is a solid at room temperature, and a linear carbonate (Fig 3), in this case dimethyl carbonate (DMC), which is not very polar but lowers viscosity. In this work, the ratio of EC to DMC was 3:7 by weight.

The salt used in this work was lithium hexafluorophosphate, $\mathrm{LiPF}_{6}$ (Fig 6), selected for its solubility in the linear carbonate electrolytes, and low cost (Xu 2004, Kawamura et al. 2005). ${ }^{11,38}$ Much of the electrolyte was soaked in a separator, made of microporous polypropylene or polyethylene, to prevent the positive and negative electrodes from making contact and shorting.

\section{Electrochemical testing}

Formation of the SEI was performed inside temperature-controlled boxes at $40.0 \pm 0.1^{\circ} \mathrm{C}$.

Charging and discharging was performed using a Maccor 4000 Series automated test system (Maccor Inc.) by charging cells to $4.3 \mathrm{~V}$ at $\mathrm{C} / 20$, holding at $4.3 \mathrm{~V}$ for $1 \mathrm{hr}$, discharging to $3.8 \mathrm{~V}$ at $\mathrm{C} / 20$, and holding at $3.8 \mathrm{~V}$ for $1 \mathrm{hr}$, where $\mathrm{C} / 20$ defines a current needed to full charge (or discharge) a cell in 20 hours.

Cells were weighed under water before and after formation, allowing the change in displacement volume, and hence quantity of gas produced, to be calculated using Archimedes principle. Before storage and cycling, cells were degassed by cutting open the pouch in the argon atmosphere glovebox, and resealing using the compact vacuum sealer. The cells were then reweighed. 


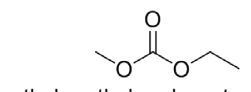

ethyl methyl carbonate (EMC)

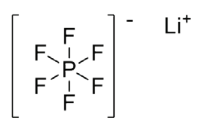

lithium hexafluorophosphate
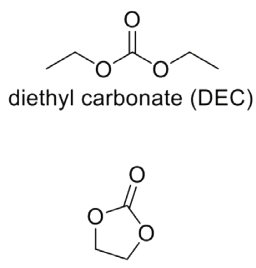

Ethylene carbonate (EC)

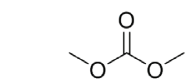

dimethyl carbonate (DMC)

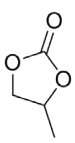

Propylene carbonate (PC)

Fig 6 Structures of common lithium ion battery electrolytes and lithium hexafluorophosphate, the lithium salt used.

Long-term cycling was performed on a Neware cycler at $40.0 \pm 0.1^{\circ} \mathrm{C}$, charged at $\mathrm{C} / 3$ to $4.3 \mathrm{~V}$, and held there until the charging current dropped below $\mathrm{C} / 20$. Cells were then discharged at $\mathrm{C} / 3$ to $2.8 \mathrm{~V}$, following which they were charged again. Every 50 cycles, a slow charge/discharge cycle was performed at $\mathrm{C} / 20$.

\section{RESULTS}

As seen in Fig 7, all of the cells produced some gas during formation, although both ternary blends, namely the $1 \% \mathrm{PDO}+1 \% \mathrm{MMDS}$ $+1 \%$ VC (PDO111V) and 2\% PDO + 1\% MMDS + 1\% TTSPi (PDO211T), produced very little gas, $0.172 \pm 0.004 \mathrm{~mL}$ and $0.23 \pm 0.05$ $\mathrm{mL}$, respectively. In fact, the PDO111V produced less gas even than the $2 \% \mathrm{VC}$, which produced $0.190 \pm 0.003 \mathrm{~mL}$. All the cells containing only PDO, except for the 4\% PDO, produced less gas than cells made without any electrolyte additive, which produced $1.3 \pm 0.2 \mathrm{~mL}$. Binary blends not containing DTD also produced little gas, with the $2 \% \mathrm{PDO}+2 \% \mathrm{VC}$ and the $2 \% \mathrm{PDO}+1 \% \mathrm{LFO}$ cells producing $0.44 \pm 0.01 \mathrm{~mL}$ and $0.522 \pm 0.009 \mathrm{~mL}$ respectively.

The PDO and DTD blends varied widely in their gas production. The lowest gas production came from $1 \%$ PDO $+2 \%$ DTD, with $0.30 \pm 0.02 \mathrm{~mL}$ of gas, while the most gas came from $4 \%$ PDO $+1 \%$ DTD, producing $1.19 \pm 0.05 \mathrm{~mL}$ of gas.

The total number of cycles required for each cell type to lose $10 \%$ of its original capacity is summarised in Fig 8. Cells with no additive performed very poorly, losing $10 \%$ of their original capacity within only 192 cycles, while those containing 2\% VC, common in many commercial cells, lasted 388 cycles. All the cells containing PDO alone outperformed the $2 \% \mathrm{VC}$ cells, lasting 675 cycles when only 


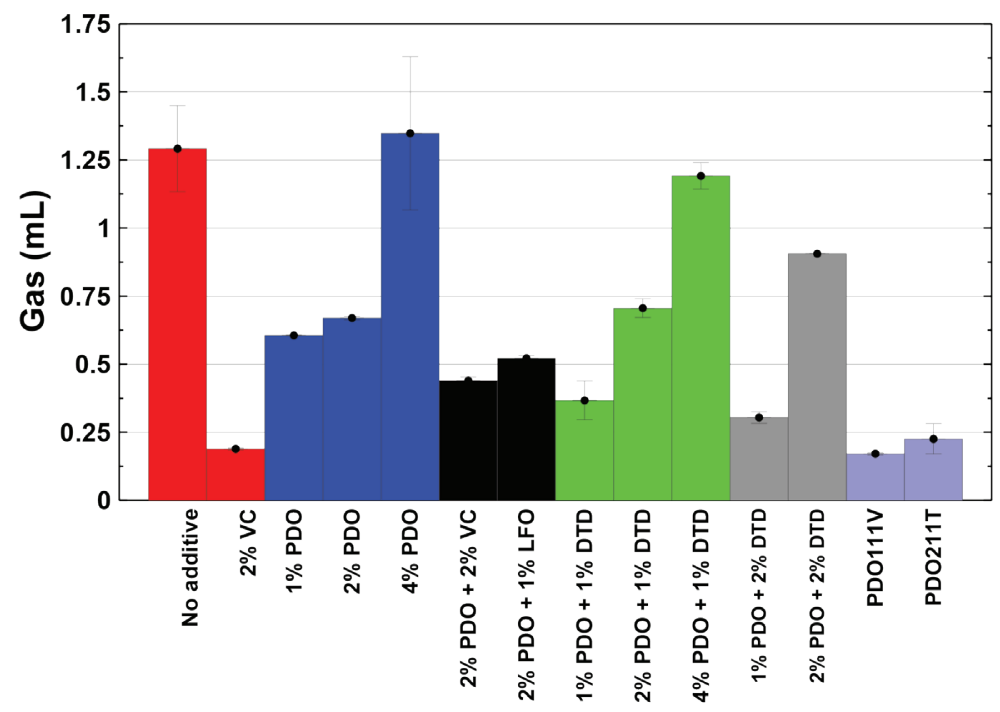

Figure 7. Quantity of gas, measured using Archimedes' principle, produced during formation of the PDO containing cells. Electrolyte composition is indicated on the figure, except for PDO111V, which is $1 \%$ PDO + 1\% MMDS + 1\% VC, and PDO211T, which is $2 \%$ PDO + 1\% MMDS + 1\% TTSPi.

$1 \%$ was used, and 714 cycles when $2 \%$ was used; the 4\% PDO cell experienced relatively rapid capacity loss by 369 cycles, so it was stopped, with $96.3 \%$ capacity remaining. $2 \%$ PDO added to $2 \% \mathrm{VC}$ increased lifespan to 551 cycles, while 2\% PDO + 1\% LFO lasted for 897 cycles. Ternary blends containing PDO were also very successful, with the PDO111V and PDO211T cells lasting 763 and 672 cycles, respectively.

The best longevity, however, came when PDO was combined with DTD. $1 \%$ PDO $+1 \%$ DTD was worse than $1 \%$ PDO, lasting 521 cycles. Increasing the DTD from $1 \%$ to $2 \%$, however, more than doubled the cell's lifespan; the cell with this electrolyte blend lasted 1265 cycles before losing $10 \%$ of its original capacity and is still cycling as of the time of this writing. $2 \%$ PDO $+1 \%$ DTD has also showed excellent capacity retention, reaching 1139 cycles before losing $10 \%$ of its original capacity. The $2 \% \mathrm{PDO}+2 \%$ DTD cell did not perform quite as well, reaching only 891 cycles, while the $4 \%$ PDO + 1\% DTD cell experienced $10 \%$ capacity loss after 791 cycles.

Fig 10 displays the normalised capacity and voltage hysteresis of cells containing PDO alone, along with a cell containing no electrolyte additive, and a cell containing only VC. 


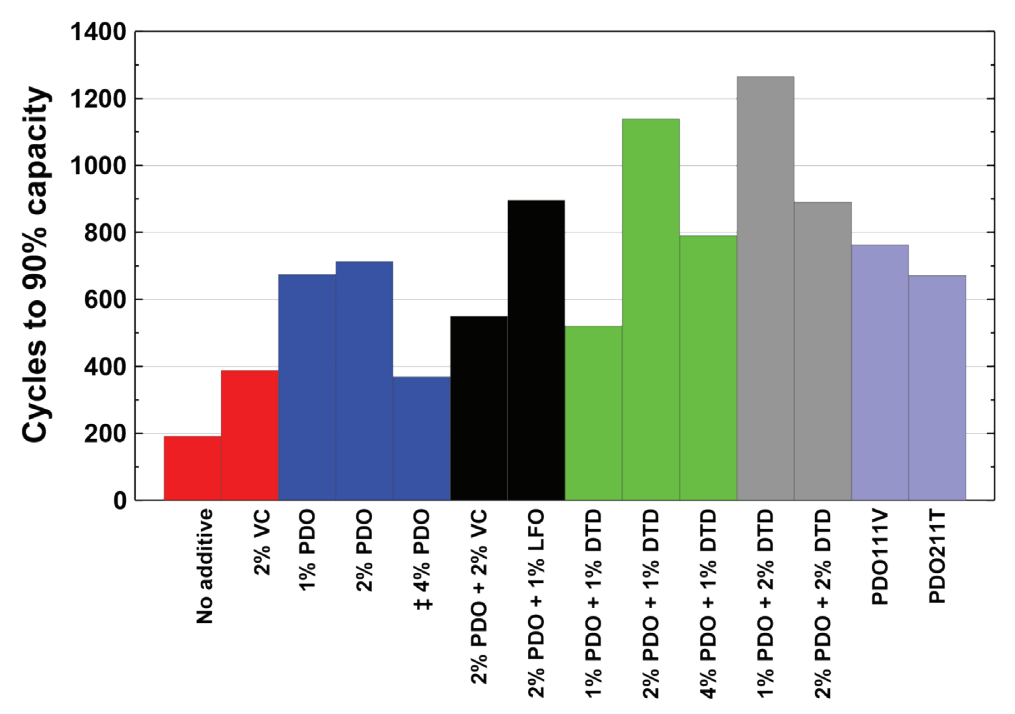

Fig 8 The total number of cycles required for a 4.3V NMC622/artificial graphite pouch cell to lose $10 \%$ of its original capacity at $400 \mathrm{C}, \mathrm{C} / 3$ charge-discharge rate. Electrolyte additive compositions are indicated on the Fig, except for PDO111V, which is $1 \%$ PDO + $1 \%$ MMDS + 1\% VC, and PDO211T, which is $2 \%$ PDO + $1 \%$ MMDS + $1 \%$ TTSPi. $\$$ : Cycling was stopped at $96.3 \%$ capacity.

Normalised capacity is calculated as seen in the equation below.

$$
\text { Normalised capacity }=\frac{\text { Capacity in } m \text { Ah at cycle } n}{\text { Capacity in } m \text { Ah at cycle } 3}
$$

The average charge and discharge voltage used to determine voltage hysteresis, a measure of the cell's impedance, is calculated from a capacity vs voltage plot. High impedance reduces the rate at which a cell can be charged and discharged, much like the way a partially clogged water pipe reduces flow rate.

Voltage hysteresis is calculated as shown in the equation below,

$$
\Delta V=V_{a v, c}-V_{a v, d}
$$

where $\Delta \mathrm{V}=$ voltage hysteresis, $\mathrm{V}_{\mathrm{av}, \mathrm{c}}=$ average charge voltage, and $\mathrm{V}_{\mathrm{av}, \mathrm{d}}=$ average discharge voltage.

An example of a capacity vs voltage plot for cycle 400 of $2 \%$ PDO $+2 \%$ VC, a cell with high hysteresis, along with $1 \%$ PDO $+2 \%$ DTD, a cell with much lower hysteresis, is shown in Fig 9. 


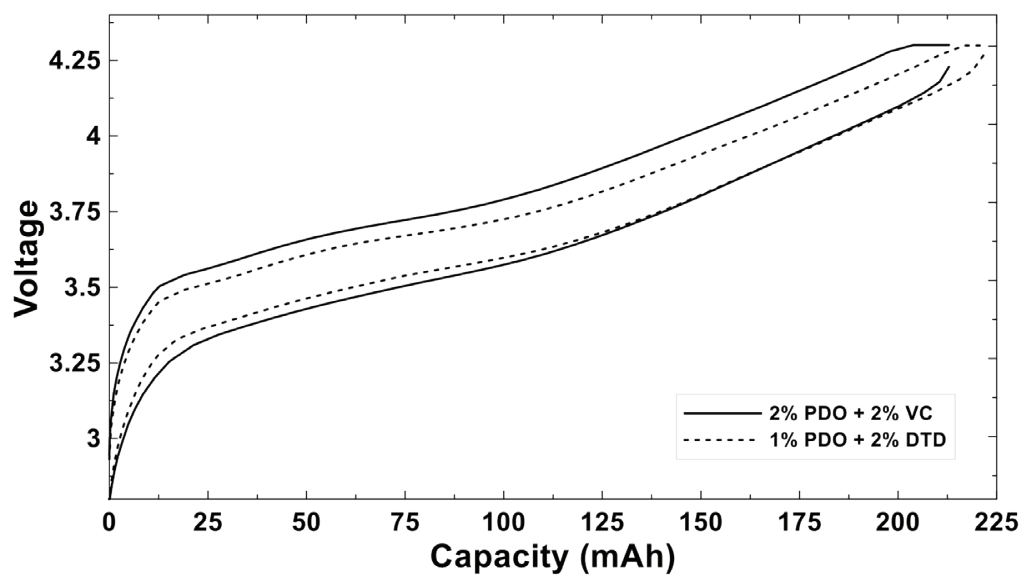

Fig 9 Voltage vs capacity plot for cycle 400 of two NMC 622/artificial graphite pouch cells, cycled to $4.3 \mathrm{~V}$ at $\mathrm{C} / 3$ charge-discharge rate and $400 \mathrm{C}$. Electrolyte additives are $2 \%$ PDO $+2 \%$ VC (a cell with high hysteresis) and $1 \%$ PDO $+2 \%$ DTD (a cell with low hysteresis).

The voltage hysteresis for that cycle is the area between the charge and discharge curves, divided by the capacity. The voltage hysteresis for this cycle is $0.2193 \mathrm{~V}$ for the $2 \% \mathrm{PDO}+2 \% \mathrm{VC}$ cell, and $0.1343 \mathrm{~V}$ for the $1 \%$ PDO $+2 \%$ DTD cell.

As seen in Fig 10, all these cells, except for the 4\% PDO cells showed better cycling behaviour and slower hysteresis growth than the $2 \% \mathrm{VC}$ and the cells made with no additive. Notably, both the cells containing VC and those with PDO showed a sudden increase in hysteresis at the same time as their capacity loss started to accelerate. Some cells, such as the 2\% PDO cell, show outlying data points; these are due to noise on the Neware charging system.

Fig 11 shows the effect of adding further additives to PDO. Once again, all the cells containing PDO outperformed the $2 \% \mathrm{VC}$ and additive-free cells. This time, none of the PDO containing cells showed a sudden drop in capacity together with a rapid increase in hysteresis. Instead, their capacity loss was much more gradual.

The best performers of all were those containing PDO and DTD. Fig 12 shows their normalised capacity and voltage hysteresis plots. Once again, the decline in capacity and increase in hysteresis for all the PDO-containing cells was gradual, except for the $1 \%$ PDO $+1 \%$ DTD, which showed a sudden drop in capacity around 500 cycles, accompanied by a quick increase in hysteresis. 


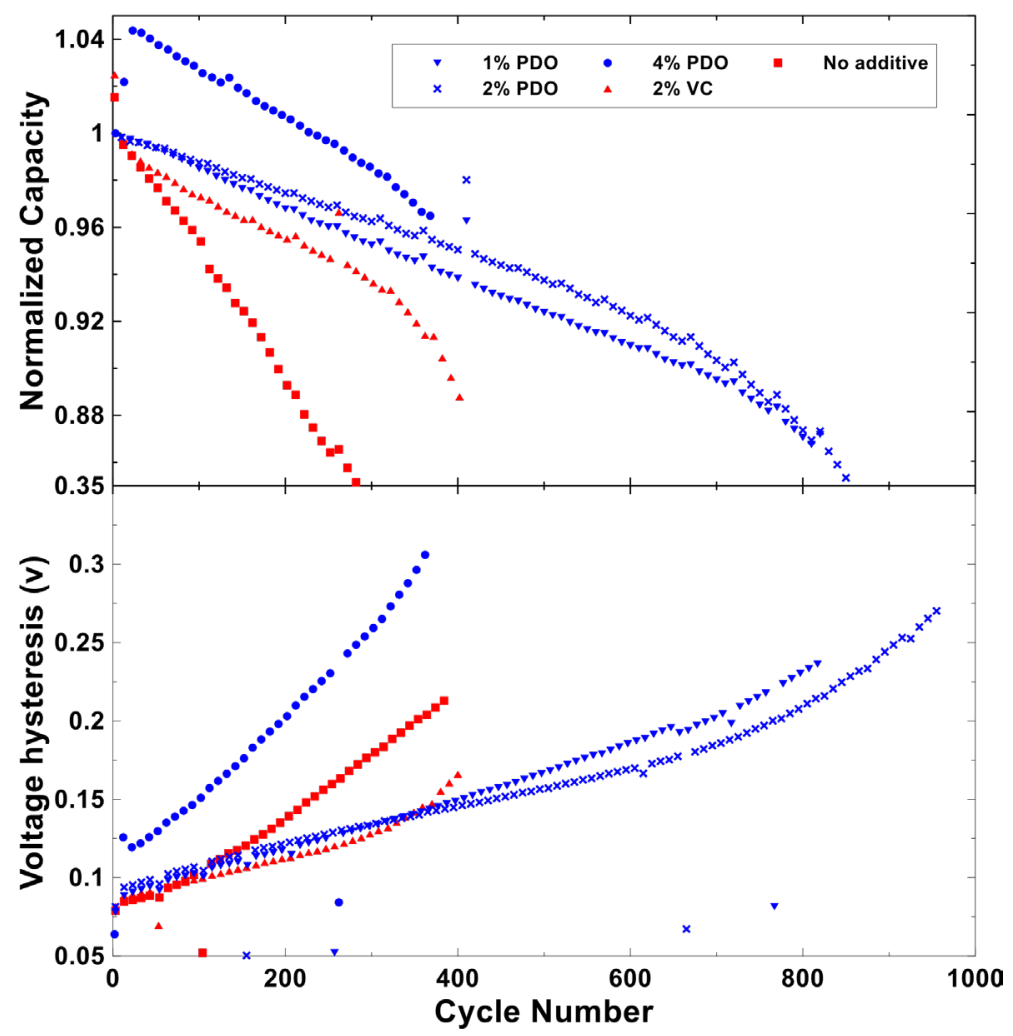

Fig 10 Normalised capacity (top) and voltage hysteresis (bottom) of NMC622/ graphite cells cycled at $400 \mathrm{C}$ and $\mathrm{C} / 3$ charge-discharge rate to $4.3 \mathrm{~V}$. Electrolyte additive concentrations are indicated on the figure.

\section{DISCUSSION}

While almost all lithium-ion batteries produce gas, consisting mostly of hydrogen and ethylene, with smaller quantities of $\mathrm{CO}_{2}, \mathrm{CO}$, and $\mathrm{CH}_{4}$ during the initial formation of the SEI (Ellis et al. 2017), it is desirable to develop cell chemistries that do not produce excessive quantities of gas. As seen in Fig 7, while all the PDO-containing cells produced more gas than commercial cells containing $2 \% \mathrm{VC}$, only the ones containing $4 \% \mathrm{PDO}$ and $4 \% \mathrm{PDO}+1 \%$ DTD produced more than $1 \mathrm{~mL}$ of gas, and these did not show the best cycling behaviour (Fig 10). Therefore, gas production in formation is not likely to be a major issue for PDO. 


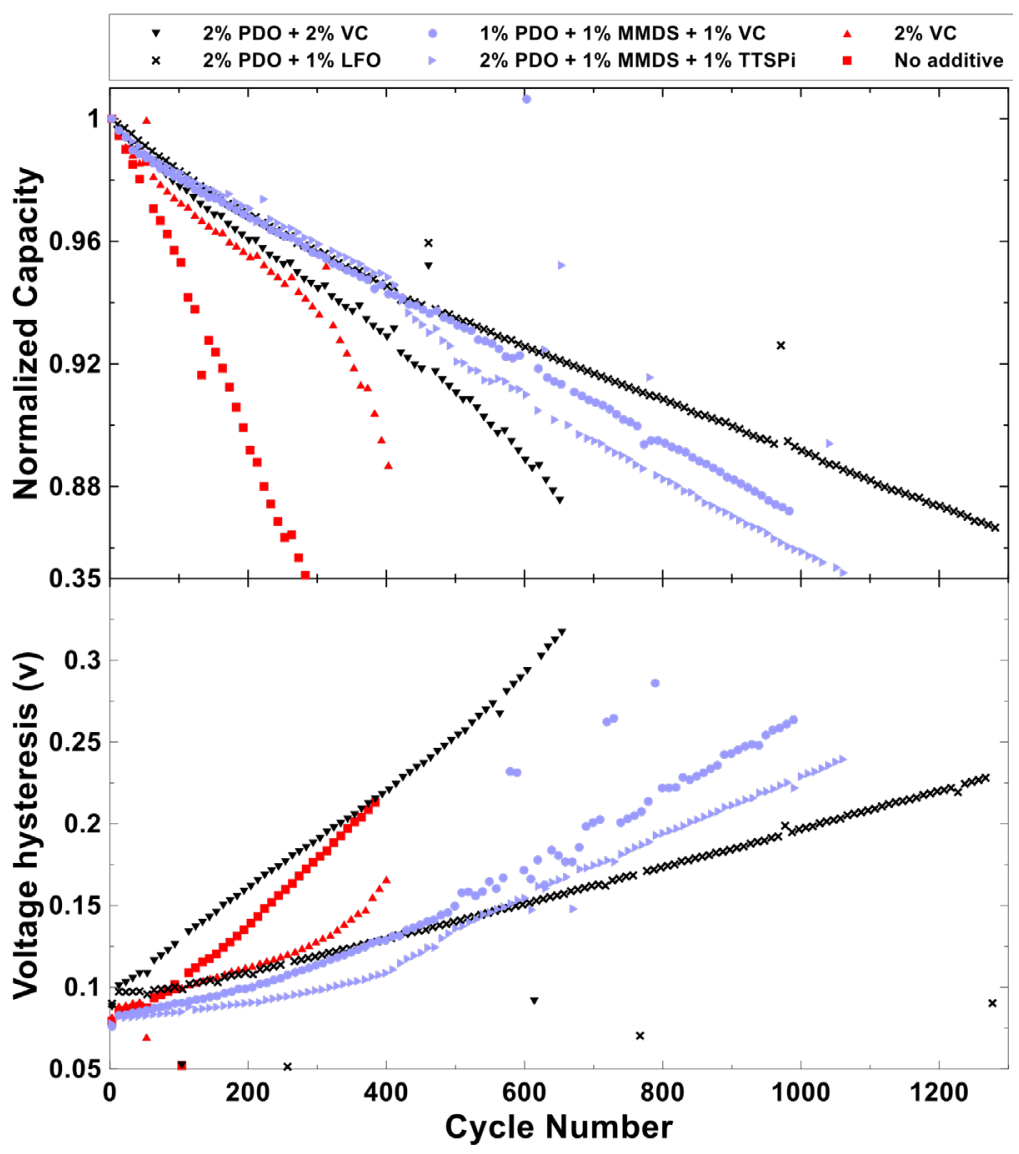

Fig 11 Normalised capacity (top) and voltage hysteresis (bottom) of NMC622/ graphite cells cycled at $400 \mathrm{C}$ and $\mathrm{C} / 3$ charge-discharge rate to $4.3 \mathrm{~V}$. Electrolyte additive concentrations are indicated on the Fig.

A cell containing no additive (Fig 8) does not perform very well, showing fast growth in hysteresis and rapid capacity loss (Fig 10). The correlation between these two is not surprising, since a rapid growth in voltage hysteresis means that the cell's impedance is growing rapidly, and this is a common cause of cell failure (Burns et al. 2013b).

Adding 2\% VC nearly doubles a cell's cycle life (Fig 8), and greatly slows the rate of hysteresis increase (Fig 10). The use of just 1\% PDO, however, produces even greater benefits, extending cycle life by about $65 \%$ when compared to $2 \% \mathrm{VC}$, and more than triple compared to a cell with no additive. Adding 2\% PDO, however, provided only 


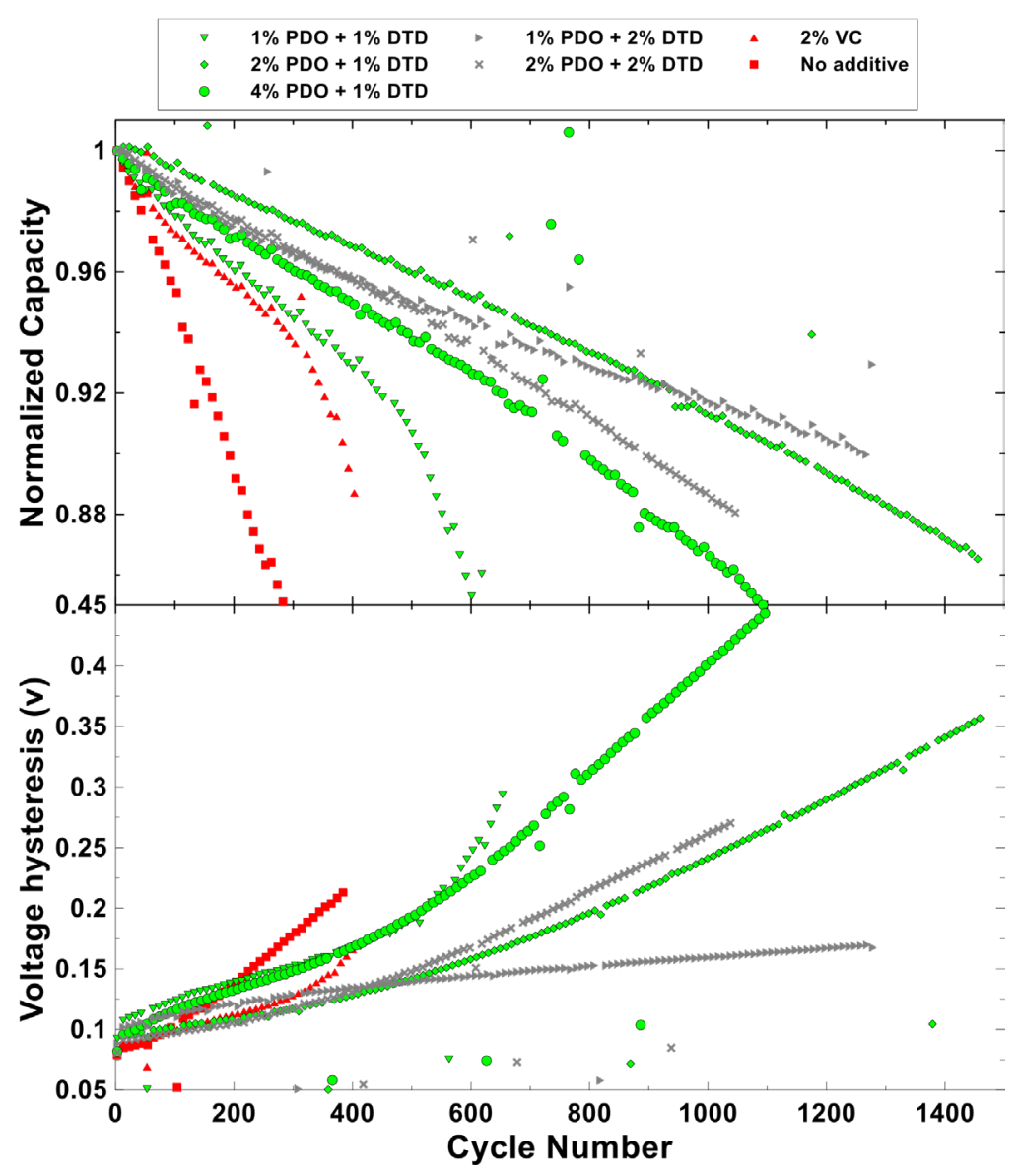

Fig 12 Normalised capacity (top) and voltage hysteresis (bottom) of NMC622/ graphite cells cycled at $400 \mathrm{C}$ and $\mathrm{C} / 3$ charge-discharge rate to $4.3 \mathrm{~V}$. Electrolyte additive concentrations are indicated on the Fig.

modest increases in cycle life (Fig 10), and did not significantly slow impedance growth compared to $1 \%$ PDO. This suggests that $1 \%$ PDO is enough to make a good SEI, and that adding extra PDO provides little to no benefit.

When the PDO concentration was increased to $4 \%$, the gas produced during formation was greatly increased, and the cell showed unusual capacity behaviour, with the capacity increasing rapidly for the first 35 cycles, before dropping sharply. Throughout this entire process, the impedance increased rapidly, a behaviour similar to that reported for 
MDO.(Hall et al. 2018) ${ }^{34}$ Adding 1\% DTD prevented the rapid initial growth in capacity, and also slowed the rate of impedance growth and capacity loss, but it was plain that $4 \%$ PDO was too much. Maybe the excess PDO was being oxidized at the positive electrode, but the reasons for this spike and subsequent crash are unknown and are an area warranting future study.

Two of the binary blends tested included $2 \% \mathrm{PDO}+2 \% \mathrm{VC}$ and $2 \%$ PDO $+1 \%$ LFO (Figs 8,11 ). The latter was one of the best cells, with slow impedance growth and long cycle life. The former cell, however, showed faster impedance growth than a cell with no additive (which would limit fast charging and discharging) and moderately fast capacity loss, likely due to the VC making an excessively thick SEI. This suggests that VC and PDO are not a good additive pair.

The best binary blends tested were those containing PDO and DTD (Figs 8, 12). While combining $1 \%$ PDO with $1 \%$ DTD was worse than using $1 \%$ PDO alone, adding $2 \%$ DTD to $1 \%$ PDO produced the best cell of all, with slow impedance growth and exceptional cycle life, demonstrating the complex interactions occurring between the components of a cell's electrolyte. Furthermore, the slope of the normalised capacity appears to slowly curve upwards, suggesting that this cell may last over 2500 cycles before experiencing $20 \%$ capacity loss - the usual criterion for a cell's end of life. The second-strongest performer was $2 \%$ PDO $+1 \%$ DTD. Unfortunately, the slope of the normalised capacity appears to be curving slightly downwards, and the voltage hysteresis plot has a slight upward curve, suggesting that this cell may experience sudden failure when its impedance becomes too great for it to continue cycling. 2\% PDO $+2 \%$ DTD came in third place, with similar capacity retention and hysteresis behaviour to $2 \%$ PDO $+1 \%$ DTD. Using 4\% PDO with 1\% DTD, however, was too much; the cell's impedance grew quickly, and its capacity declined quickly.

The cell containing the ternary blend of PDO111V showed slower impedance growth and capacity loss than the $2 \% \mathrm{PDO}+2 \% \mathrm{VC}$ (Figs $8,11)$, but it still was only a moderately good performer when compared to the PDO/DTD blends. Another ternary blend, PDO211T, also showed very low gas production in formation, and slower impedance growth than PDO211V, but it lost capacity faster. However, the rate of capacity loss of PDO211T appears to slowly be decreasing, and it may, in time, show slower capacity loss than PDO111V. Most interestingly, the ternary blend of PDO211T showed a dramatic increase in 
impedance around 400 cycles, but this rapid rise in impedance slowed somewhat around 600 cycles, possibly due to the consumption of one of the three additives.

The exact reason why $1 \% \mathrm{PDO}+2 \% \mathrm{DTD}$ is such a good electrolyte additive blend is not known, but it may be because PDO forms an excellent SEI on the negative electrode but is susceptible to oxidation on the positive electrode, and that adding DTD forms a protective film on the positive electrode, protecting PDO from oxidation at high cell potential. This may also be the reason why adding $2 \%$ PDO produces little benefit when PDO is used by itself, as the excess PDO that does not go into forming an SEI gets oxidized at the positive electrode. This could make products that degrade the cell (Xiong et al. 2017, Xiong et al. 2016)' and that this problem is made worse when even more PDO is used.

A disturbing trend observed for some cells, namely the $2 \% \mathrm{VC}, 1 \%$ PDO, $2 \%$ PDO, and $1 \%$ PDO $+1 \%$ DTD cells was their mechanism of failure. Instead of showing a gradual decline in capacity throughout their cycle life, these cells showed a slow and gradual loss of capacity initially (Figs 10, 12), followed by a sudden increase in hysteresis and drop in capacity, a mechanism known as rollover failure (Burns et al. 2013b). This is problematic for the consumer, because it means that a cell can go from having good capacity retention to failure within relatively few cycles, with little to no advance warning. Luckily, the best performing blend, $1 \%$ PDO $+2 \%$ DTD, showed no sign of this behaviour.

\section{CONCLUSION}

A new electrolyte additive, PDO, was chemically synthesized and tested in lithium-ion cells. In moderate quantities, PDO is an excellent electrolyte additive, especially when used in combination with DTD, with the combination of $1 \%$ PDO $+2 \%$ DTD by weight showing excellent long-term cycling behaviour along with low gas production in formation and slow impedance growth in cycling. Combining PDO and $\mathrm{VC}$, as well as using 4\% PDO, should be avoided, as these blends do not show as good a cycle life as the PDO/DTD blends. Additionally, the precise ratio of PDO to DTD is very important, since $2 \%$ PDO $+1 \%$ DTD and $1 \%$ PDO $+2 \%$ DTD are very good blends, but other ratios of PDO to DTD, such as $1 \%$ PDO $+1 \%$ DTD, are not as good. 
Finally, all the PDO-containing cells outperformed cells containing $2 \% \mathrm{VC}$, a common additive used commercially. Due to the promising results obtained for PDO, a patent has been filed on the use of PDO and related molecules as additives in Li-ion batteries (Hall et al. 2019).

Acknowledgements I would like to thank Dr. David Hall, Dr. Xiowei Ma, Jazmin Baltazar, and Katherine Lin for assisting with the filling, cycling, and degassing of many of the cells used in this paper, as well as Dr. Jeff Dahn, Dr. David Hall, and Patricia StoffynEgli for reviewing it. I would also like to thank Dr. Deijun Xiong of Shenzhen Capchem for supplying the $\mathrm{Li}_{2} \mathrm{PO}_{2} \mathrm{~F}_{2}$ used in this paper, and NSERC and Tesla Canada for funding my research.

\section{REFERENCES}

The author has used the ACS (American Chemical Society) format for their citation and this was deemed acceptable by the Editor.

Aurbach, D., Gamolsky, K., Markovsky, B., Gofer, Y., Schmidt, M. \& Heider, U. (2002). On the use of vinylene carbonate (VC) as an additive to electrolyte solutions for Li-ion batteries. Electrochimica Acta 47, 1423-1439.

Burns, J.C., Petibon, R., Nelson, K.J., Sinha, N.N., Kassam, A., Way, B.M. \& Dahn, J.R. (2013a). Studies of the Effect of Varying Vinylene Carbonate (VC) Content in Lithium Ion Cells on Cycling Performance and Cell Impedance. J. Electrochem. Soc. 160, A1668-A1674.

Burns, J.C., Kassam, A., Sinha, N.N., Downie, L.E., Solnickova, L., Way, B.M. \& Dahn, J.R. (2013b). Predicting and Extending the Lifetime of Li-Ion Batteries. J. Electrochem. Soc. 160, A1451-A1456.

Dahn, J.R. (2018). Our Energy Future, Lithium-Ion Batteries and Electrochemical Energy Storage. www.dal.ca/faculty/science/news-events/ events/2018/09/27/faculty_of_science_bicentennial_lecture.html.

Ecker, M., Nieto, N., Käbitz, S., Schmalstieg, J., Blānke, H., Warnecke, A. \& Sauer, D.U. (2014). Calendar and cycle life study of Li(NiMnCo) O2-based 18650 lithium-ion batteries. J. Power Sources 248, 839-851.

Ellis, L.D., Allen, J. P., Thompson, L.M., Harlow, J.E., Stone, W.J., Hill, I.G. \& Dahn, J.R. (2017). Quantifying, Understanding and Evaluating the Effects of Gas Consumption in LithiumIon Cells. J. Electrochem. Soc. 164, A3518-A3528.

Etacheri, V., Haik, O., Goffer, Y., Roberts, G.A., Stefan, I.C., Fasching, R. \& Aurbach, D. (2012). Effect of Fluoroethylene Carbonate (FEC) on the Performance and Surface Chemistry of SiNanowire Li-Ion Battery Anodes. Langmuir 28, 965-976. 
Gordon, J. \& Grebler, Dan. B.C. (2018). Moves to phase out non-electric car sales by 2040 . Weather Network. www.theweathernetwork.com/news/ articles/british-columbiaelectric-vehicles-car-2014-law/117455.

Hall, D.S., Hynes, T. \& Dahn, J.R. (2018). Dioxazolone and Nitrile Sulfite Electrolyte Additives for Lithium-Ion Cells. J. Electrochem. Soc. 165, A2961-A2967.

Hall, D.S., Hynes, T. \& Dahn, J.R. (2019). Dioxazoles and Nitrile Sulfites as Electrolyte Additives for Lithium-ion Batteries (Patent filed).

Han, Y.-K., Yoo, J. \& Yim, T. (2015). Why is tris(trimethylsilyl) phosphite effective as an additive for high-voltage lithium-ion batteries? J. Mater. Chem. A 3, 10900-10909.

Hong, S., Hong, B., Song, W., Qin, Z., Duan, B., Lai, Y. \& Jiang, F. (2018). Communication - Lithium Difluorophosphate as an Electrolyte Additive to Improve the High Voltage Performance of $\mathrm{LiNi}_{0.5} \mathrm{Co}_{0.2}$ $\mathrm{Mn}_{03} \mathrm{O}_{2} /$ Graphite Cell. J. Electrochem. Soc. 165, A368- A370).

Jin, Y., Kneusels, N.-J. H., Marbella, L.E., Castillo-Martínez, E., Magusin, P.C. M. M., Weatherup, R.S., Jónsson, E., Liu, T., Paul, S. \& Grey, C.P. (2018). Understanding Fluoroethylene Carbonate and Vinylene Carbonate Based Electrolytes for Si Anodes in Lithium Ion Batteries with NMR Spectroscopy. J. Am. Chem. Soc. 140, 9854-9867.

Kawamura, T., Tanaka, T., Egashira, M., Watanabe, I., Okada, S. \& Yamaki, J. (2005). Methyl Difluoroacetate Inhibits Corrosion of Aluminum Cathode Current Collector for Lithium Ion Cells. Electrochem. Solid-State Lett. 8, A459.

Koo, B., Lee, J., Lee, Y., Kim, J.K. \& Choi, N.-S. (2015). Vinylene carbonate and tris(trimethylsilyl) phosphite hybrid additives to improve the electrochemical performance of spinel lithium manganese oxide/graphite cells at $60^{\circ} \mathrm{C}$. Electrochimica Acta 173, 750-756.

Lee, H.-H., Wang, Y.-Y., Wan, C.-C., Yang, M.-H., Wu, H.-C. \& Shieh, D.-T. (2005). The function of vinylene carbonate as a thermal additive to electrolyte in lithium batteries. J. Appl. Electrochem. 35, 615-623.

Li, X., Yin, Z., Li, X. \& Wang, C. (2014). Ethylene sulfate as film formation additive to improve the compatibility of graphite electrode for lithium-ion battery. Ionics 20, 795-801.

Liu, Q.Q., Ma, L., Du, C.Y. \& Dahn, J.R. (2018). Effects of the LiPO2F2 additive on unwanted lithium plating in lithium-ion cells. Electrochimica Acta 263, 237-248.

Louli, A.J. (20127). Probing the Reversible and Irreversible Volume Expansion Observed in Li-ion Pouch Cells.

Ma, L., Xia, J., Xia, X. \& Dahn, J.R. (2014). The Impact of Vinylene Carbonate, Fluoroethylene Carbonate and Vinyl Ethylene Carbonate Electrolyte Additives on Electrode/Electrolyte Reactivity Studied Using Accelerating Rate Calorimetry. J. Electrochem. Soc. 161, A1495-A1498.

Mai, S., Xu, M., Liao, X., Hu, J., Lin, H., Xing, L., Liao, Y., Li, X. \& Li, W. (2014). Tris(trimethylsilyl)phosphite as electrolyte additive for high voltage layered lithium nickel cobalt manganese oxide cathode of lithium ion battery. Electrochimica Acta 147, 565-571. 
Madec, L., Xia, J., Petibon, R., Nelson, K.J., Sun, J.-P., Hill, I.G. \& Dahn, J.R. (2014). Effect of Sulfate Electrolyte Additives on $\mathrm{LiNi}_{1 / 3}$ $\mathrm{Mn}_{1 / 3} \mathrm{Co}_{1 / 3} \mathrm{O}_{2} /$ Graphite Pouch Cell Lifetime: Correlation between XPS Surface Studies and Electrochemical Test Results. J. Phys. Chem. C 118, 29608-29622.

Nielson, E.G. (2018). Denmark embraces electric car revolution with petrol and diesel ban plan. Reuters at www.reuters.com/article/us-denmark-autos/ denmark-embraces-electriccar-revolution-with-petrol-and-diesel-banplan-idUSKCN1MC121

Park, Y., Park, K.T., Kim, J.G. \& Chang, S. (2015). Mechanistic Studies on the Rh(III)-Mediated Amido Transfer Process Leading to Robust C-H Amination with a New Type of Amidating Reagent. J. Am. Chem. Soc. 137, 4534-4542.

Petibon, R., Rotermund, L.M. \& Dahn, J.R. (2015). Evaluation of phenyl carbonates as electrolyte additives in lithium-ion batteries. J. Power Sources 287, 184-195.

Röser, S., Lerchen, A., Ibing, L., Cao, X., Kasnatscheew, J., Glorius, F., Winter, M. \& Wagner, R. (2017). Highly Effective Solid Electrolyte Interphase-Forming Electrolyte Additive Enabling High Voltage LithiumIon Batteries. Chem. Mater. 29, 7733-7739.

Ryou, M.-H., Han, G.-B., Lee, Y. M., Lee, J.-N., Lee, D.J., Yoon, Y.O. \& Park, J.-K. (2010). Effect of fluoroethylene carbonate on high temperature capacity retention of LiMn2O4/graphite Liion cells. Electrochimica Acta 55, 2073-2077.

Seo, D.M., Chalasani, D., Parimalam, B.S., Kadam, R., Nie, M. \& Lucht, B.L. (2014). Reduction Reactions of Carbonate Solvents for Lithium Ion Batteries. ECS Electrochem. Lett. 3, A91- A93.

Tesla. (2019). Model 3 | Tesla. at www.tesla.com/en_CA/model3.

Trask, S.E., Li, Y., Kubal, J.J., Bettge, M., Polzin, B.J., Zhu, Y., Jansen, A.N. \& Abraham, D.P. (2014). From coin cells to $400 \mathrm{mAh}$ pouch cells: Enhancing performance of high-capacity lithium-ion cells via modifications in electrode constitution and fabrication. J. Power Sources 259, 233-244.

Verma, P., Maire, P. \& Novák, P. (2010). A review of the features and analyses of the solid electrolyte interphase in Li-ion batteries. Electrochimica Acta 55, 6332-6341.

Wang, D.Y., Xia, J., Ma, L., Nelson, K.J., Harlow, J.E., Xiong, D., Downie, L.E., Petibon, R., Burns, J.C., Xiao, A., Lamanna, W.M. \& Dahn, J.R. (2014a). A Systematic Study of Electrolyte Additives in $\mathrm{Li}\left[\mathrm{Ni}_{1 / 3} \mathrm{Mn}_{1 / 3}\right.$ $\left.\mathrm{Co}_{1 / 3}\right] \mathrm{O}_{2}(\mathrm{NMC}) /$ Graphite Pouch Cells. J. Electrochem. Soc. 161, A1818A1827.

Wang, D.Y., Sinha, N.N., Burns, J.C., Aiken, C.P., Petibon, R. \& Dahn, J.R. (2014b). A Comparative Study of Vinylene Carbonate and Fluoroethylene Carbonate Additives for $\mathrm{LiCoO}_{2} / \mathrm{Graphite}$ Pouch Cells. J. Electrochem. Soc. 161, A467-A472. 
Xia, J., Ma, L., Aiken, C.P., Nelson, K.J., Chen, L.P. \& Dahn, J.R. (2014a). Comparative Study on Prop-1-ene-1,3-sultone and Vinylene Carbonate as Electrolyte Additives for $\mathrm{Li}\left(\mathrm{Ni}_{1 / 3} \mathrm{Mn}_{13} \mathrm{Co}_{1 / 3}\right) \mathrm{O}_{2} /$ Graphite Pouch Cells. J. Electrochem. Soc. 161, A1634-A1641.

Xia, J., Sinha, N.N., Chen, L.P. \& Dahn, J.R. (2014b). A Comparative Study of a Family of Sulfate Electrolyte Additives. J. Electrochem. Soc. 161, A264-A274.

Xia, J., Harlow, J.E., Petibon, R., Burns, J.C., Chen, L.P. \& Dahn, J.R. (2014c). Comparative Study on Methylene Methyl Disulfonate (MMDS) and 1,3-Propane Sultone (PS) as Electrolyte Additives for Li-Ion Batteries. J. Electrochem. Soc. 161, A547-A553.

Xia, J., Ma, L. \& Dahn, J.R. (2015). Improving the long-term cycling performance of lithium-ion batteries at elevated temperature with electrolyte additives. J. Power Sources 287, 377-385.

Xiong, D.J., Petibon, R., Nie, M., Ma, L., Xia, J. \& Dahn, J.R. (2016). Interactions between Positive and Negative Electrodes in Li-Ion Cells Operated at High Temperature and High Voltage. J. Electrochem. Soc. 163, A546-A551.

Xiong, D.J., Ellis, L.D., Petibon, R., Hynes, T., Liu, Q.Q. \& Dahn, J.R. (2017). Studies of Gas Generation, Gas Consumption and Impedance Growth in Li-Ion Cells with Carbonate or Fluorinated Electrolytes Using the Pouch Bag Method. J. Electrochem. Soc. 164, A340-A347.

Xu, K. (2004). Nonaqueous Liquid Electrolytes for Lithium-Based Rechargeable Batteries. Chem. Rev. 104, 4303-4418.

Xu, K. (2014). Electrolytes and Interphases in Li-Ion Batteries and Beyond. Chem. Rev. 114, 11503-11618.

Yim, T. \& Han, Y.-K. (2017). Tris(trimethylsilyl) Phosphite as an Efficient Electrolyte Additive To Improve the Surface Stability of Graphite Anodes. ACS Appl. Mater. Interfaces 9, 32851-32858.

Zhao, W., Zheng, G., Lin, M., Zhao, W., Li, D., Guan, X., Ji, Y., Ortiz, G.F. \& Yang, Y. (2018). Toward a stable solid-electrolyte-interfaces on nickelrich cathodes: LiPO 2 F 2 salt-type additive and its working mechanism for LiNi 0.5 Mn 0.25 Co 0.25 O 2 cathodes. J. Power Sources 380, 149-157. 